\title{
RANCANG BANGUN APLIKASI ASESMEN ANAK BERKEBUTUHAN KHUSUS PADA SEKOLAH INKLUSIF
}

\author{
Mirza Yogy Kurniawan'), Wagino ${ }^{2)}$, M. Dedy Rosyadi ${ }^{3)}$ \\ ${ }^{1,2,3)}$ Program Studi Teknik Informatika UNISKA MAB Banjarmasin \\ Jl. Adhyaksa No. 2 Kayu Tangi - Banjarmasin \\ e-mail: mirza@fti.uniska-bjm.ac.id ${ }^{1)}$, ginouniska@gmail.com ${ }^{2)}$, dedy.rosyadi@gmail.com ${ }^{3)}$
}

\begin{abstract}
ABSTRAK
Pendidikan inklusif adalah penyelenggaraan pendidikan yang tidak membatasi antara siswa normal dan siswa yang memiliki hambatan tertentu. Asesmen pada pendidikan inklusif dilakukan untuk memahami kebutuhan, menentukan derajat hambatan, dan menentukan model penanganan yang tepat bagi siswa berkebutuhan khusus. Kegiatan asesmen melibatkan dokumen yang cukup banyak, baik dalam hal biodata maupun juga instrumen asesmennya, ditambah terbatasnya jumpah guru pendamping khusus, sehingga diperlukan sebuah sistem yang mengelola data tersebut untuk mempermudah proses dokumentasi, analisis hasil asesmen, dan penyajian data hasil asesmennya. Aplikasi web dipilih untuk menyelesaikan permasalahan ini karena mudah untuk dioperasikan dan dapat diakses secara online tanpa harus mendatangi sekolah penyelenggara pendidikan inklusif. Aplikasi dibangun dengan memperhatikan siklus hidup sistem dengan metode Incremental Model dimana model dirancang, diimplementasikan, dan diuji secara bertahap dengan penambahan sedikit demi sedikit pada tiap tahapan sampai produk perangkat lunak selesai dibuat. Sistem yang dihasilkan mampu mempermudah dokumentasi kegiatan asesmen, proses analisis, dan penyajian hasil asesmen tersebut.
\end{abstract}

Kata Kunci: : Anak berkebutuhan khusus, Asesmen, Aplikasi Web

\begin{abstract}
Inclusive education is a form of education practice mixing normal students and special needs one. Assessment of inclusive education is held to understand needs, determine the degree of obstacle, and determine the appropriate treatment model for students with special needs. The assessment involved a large number of documents including profile of students, and assessment instruments, while the other problem is the lackness of special teacher for special needs. so that a system that managed the data was needed to facilitate the documentation process, analysis of assessment results, and presentation of data from the assessment. The web application is chosen to solve this problem because it is easy to operate and can be accessed online without having to go to the school. The web application is built on Incremental Model Life Cycle that is designed, implemented, and tested gradually until completed. The resulting system is able to easily manage assessment activities, analysis processes, and presentation of the results of the assessment.
\end{abstract}

Keywords: Assesment, Child with special needs, Web Application

\section{PENDAHULUAN}

PENDIDIKAN inklusif adalah praktek pendidikan terhadap semua siswa termasuk siswa yang mengalami hambatan parah maupun majemuk disekolah reguler yang umumnya diisi oleh anak tidak berkebutuhan khusus. Praktek pendidikan inklusif diselenggarakan demi pemenuhan hak asasi manusia atas manusia tanpa adanya diskriminasi dengan memberikan pendidikan berkualitas kepada semua anak tanpa pengecualian semua anak memiliki kesempatan yang sama untuk mengembangkan potensi pribadinya dalam lingkungan yang sama [1].

Sekolah dapat melakukan kegiatan asesmen untuk memahami kebutuhan Anak Berkebutuhan Khusus (ABK). Kegiatan asesemen dapat menggali data dan informasi tentang kemampuan, kesulitan, dan kebutuhan ABK agar dapat dipilih metode yang tepat untuk penanganannya [2]. Meskipun sekolah inklusif menerima ABK sebagai siswa namun kurangnya Guru Pendamping Khusus (GPK) yang berkonsentrasi dibidang pendidikan luar biasa berpotensi menimbulkan kesalahan dalam penanganan ABK baik dalam hal asesmennya sampai dengan metode pengajarannya.

Proses asesmen secara umum dapat dibagi menjadi dua kelompok yaitu asesmen akademik yang menekankan pada upaya pengukuran capaian prestasi belajar siswa seperti pada kemampuan membaca, menulis, dan berhitung. Sedangkan kelompok lainnya adalah asesmen perkembangan yang mengutamakan pada aspek-aspek yang berkaitan dengan keterampilan prasyarat yang diperlukan untuk keberhasilan bidang akademik.

Panjangnya proses asesmen dari penyusunan instrumen, pelaksanaan asesmen, sampai dengan analisis hasil asesmen memerlukan pengarsipan yang handal dan efisien. Pengarsipan yang efisien bisa dihasilkan dengan menggunakan digitalisasi arsip, sehingga arsip tersimpan dengan rapi, tanpa kertas, memudah pencarian kembali, dan mengurangi kesalahan yang disebabkan oleh manusia.

Proses analisis hasil asesmen memerlukan GPK yang memiliki pengetahuan yang terkait dengan pendidikan luar 
biasa yang mana pada umumnya sekolah inklusif masih kekurangan guru pembimbing bidang ini. Aplikasi komputer akan mampu menerjemahkan proses analisis hasil asesmen ABK berdasarkan pengetahuan tentang pendidikan luar biasa sehingga dapat mengatasi permasalahan kurangnya jumlah GPK dengan spesifikasi keahlian tersebut.

Pada [3] identifikasi anak autis tidak lagi bersifat manual yang berdasarkan kepada identifikasi dan penilaian psikolog. Dengan sistem berbasis web yang mengacu kepada data dari psikolog dan guru SLB maka orang tua dapat mengetahui kondisi anak autis lebih dini. Sistem ini juga memberikan informasi dan gambaran umum tentang anak autis dan metode terapi bagi anak autis yang sesuai dengan sang anak.

Pemanfaatan teknologi informasi untuk mengklasifikasi ABK juga dilakukan oleh [4] yang dibangun dalam bentuk aplikasi sistem pakar. Sistem pakar yang meniru pengetahuan manusia kedalam komputer dapat mengatasi kealpaan pakar. Sistem pakar juga mampu mengambil kesimpulan dengan konsisten tanpa terpengaruh faktor lain, juga dapat bekerja terus menerus selama komputer dapat dinyalakan.

Dikemukakan oleh [5]bahwa proses asesmen yang masih manual membutuhkan banyak waktu. Proses asesmen juga menjadi subjektif karena terlalu banyak pasien yang ingin segera dilayani. Masalah tersebut diatasi dengan pembuatan Sistem Penunjang Keputusan (SPK) yang dapat menentukan terapi yang dibutuhkan oleh ABK secara obyektif dan konsisten. SPK memeberikan bobot pada kriteria tertentu sehingga mampu memberi perangkingan pada alternatif terapi yang bisa dipilih.

Asesmen yang dilaksanakan dengan berbasis komputer akan memudahkan proses pembuatan instrumen, dokumentasi riwayat asesmen, pelaksanaan asesmen tanpa kertas, dan analisis hasil asesmen yang didokumentasikan oleh aplikasi sehingga memudahkan, meningkatkan akurasi, dan mempercepat proses analisis asesmen ABK.

\section{LANDASAN TEORI}

\section{A. Anak Berkebutuhan Khusus}

Definisi Anak Berkebutuhan Khusus (ABK) lebih luas bila dibandingkan dengan anak luar biasa. Menurut [6] ABK adalah anak yang dalam kegiatan pendidikannya memerlukan layanan tertentu yang berbeda dengan anak pada umumnya. ABK mengalami hambatan dalam belajar dan perkembangan sehingga memerlukan layanan pendidikan yang sesuai yang mampu memenuhi kebutuhan spesifiknya. Sedangkan menurut [7] ABK adalah anak yang secara signifikan mengalami kelainan atau penyimpangan baik secara fisik, mental-intelektual, sosial, dan emosional dalam proses pertumbuhan dan atau perkembangannya dibandingkan dengan anak-anak lain seusianya sehingga memerlukan pelayanan pendidikan khusus.

\section{B. Pendidikan Inklusif}

Inklusif adalah praktek pendidikan yang memberikan semua siswa, termasuk yang mengalami hambatan yang parah ataupun majemuk pada sekolah reguler yang biasa didatangi oleh anak-anak non berkebutuhan khusus. Pendidikan ini bertujuan untuk membantu mempercepat program wajib belajar pendidikan dasar serta membantu meningkatkan mutu pedidikan dasar dan menengah dengan menekan angka tinggal kelas dan putus sekolah pada seluruh warga negara. Inklusif juga bertujuan sebagai pemenuhan hak asasi manusia atas pendidikan dengan memberikan kesempatan pendidikan tanpa adanya diskriminasi [1].

\section{Identifikasi dan Asesmen}

Identifikasi adalah proses menemukenali dan menetapkan berbagai strategi tindakan layanan pendidikan bagi anak dengan kebutuhan pendidikan khusus melalui serangkaian pendekatan, teknik dan proses. Proses ini merupakan proses pengenalan kebutuhan, batasan, dan kemampuan menerima ABK sebelum diselenggarakan pendidikan inklusif [8].

Asesmen adalah proses pengumpulan informasi dengan menggunakan alat dan teknik yang sesuai untuk membuat keputusan pendidikan berkenaan dengan penempatan dan program pendidikan bagi siswa tertentu. Proses ini sama halnya dengan identifikasi namun dengan analisis yang lebih mendalam tentang cara belajar yang sesuai dengan kebutuhan dan kelebihan ABK.

\section{Metode PENELITIAN}

\section{A. Tahapan Penelitian}

Penelitian ini melalui beberapa tahapan yang dilakukan agar dapat menghasilkan aplikasi yang mampu menyelesaikan permasalahan pada proses identifikasi dan asesmen $\mathrm{ABK}$, berikut tahapan yang harus dilalui :

1. Identifikasi masalah yang akan diteliti, tahapan ini menganalisis kendala apa saja yang ditemui pada proses identifikasi dan asesmen ABK, kemudian ditentukan kendala apa saja yang dapat diselesaikan dengan 
menggunakan aplikasi komputer.

2. Analisis kebutuhan sistem, pada tahapan ini akan ditentukan berbagai inputan yang akan terlibat dalam sistem kemudian ditentukan juga proses yang dikerjakan oleh aplikasi, dan juga luaran yang ingin dihasilkan. Tahapan ini juga menganalisis kebutuhan spesifikasi perangkat lunak dan juga perangkat keras.

3. Perancangan sistem, pada tahapan ini aplikasi mulai dirancang antarmukanya dalam bentuk sketsa atau mock-up, dirancang databasenya dengan kamus data, dan didokumentasikan sebelum dilanjutkan pada tahapan berikutnya.

4. Penulisan kode, setelah semua rancangan selesai maka dilanjutkan pada proses pembuatan aplikasinya, pada penelitian ini menggunakan bahasa PHP dan basis data MySQL.

5. Pengujian dan verifikasi, pada tahapan ini dilakukan pengujian terhadap aplikasi untuk memeriksa seluruh fungsi yang terdapat didalamnya agar aplikasi terbebas dari kesalahan. Verifikasi dilakukan terhadap aplikasi agar hasil yang didapat akan menyelesaikan masalah dengan tepat.

6. Implementasi pada lokasi penelitian, aplikasi akan diimplementasikan untuk dijalankan pada kondisi yang sebenarnya pada lokasi penelitian sehingga dapat digunakan pada kasus nyata.

7. Pengujian terhadap penerimaan pengguna, pada tahapan ini akan dilakukan pengujian terhadap tingkat penerimaan oleh pengguna pada lokasi penelitian, dan diukur sejauh mana aplikasi membantu proses identifikasi dan asesmen ABK.

\section{B. Rancangan Kegiatan Asesmen}

Kegiatan asesmen dimulai dari anak mendaftar pada Penerimaan Siswa Baru (PSB), kemudian dilakukan identifikasi hambatannya, selanjutnya dilakukan asesmen yang dilakukan oleh guru dan orang tua yang berikutnya hasil dari asesmen tersebut dianalisis oleh GPK dan hasilnya berupa catatan dan rekomendasi pola belajar dari GPK diserahkan kepada orang tua dan guru. Alur kegiatan asesmen ditunjukkan oleh Gambar 1.

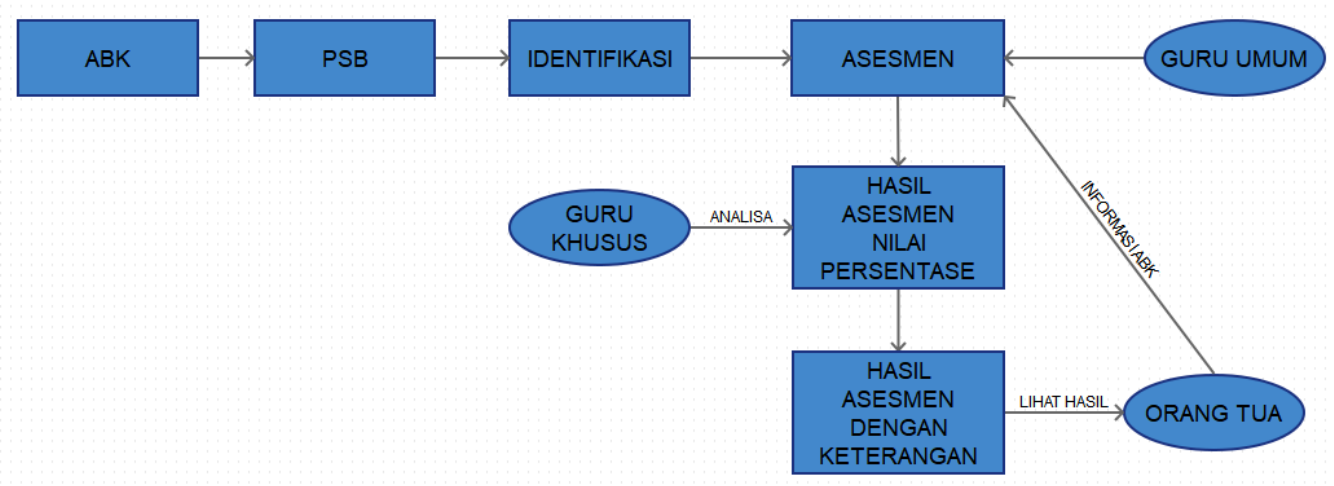

Gambar. 1. Alur Kegiatan Asesmen

\section{Rancangan Sistem}

Sistem dibangun dengan 3 (tiga) pihak yang terlibat yang memiliki peran masing-masing terhadap data yang diinput maupun laporan yang diterima. Diagram konteks dari sistem yang dibangun dapat dilihat pada Gambar 2.

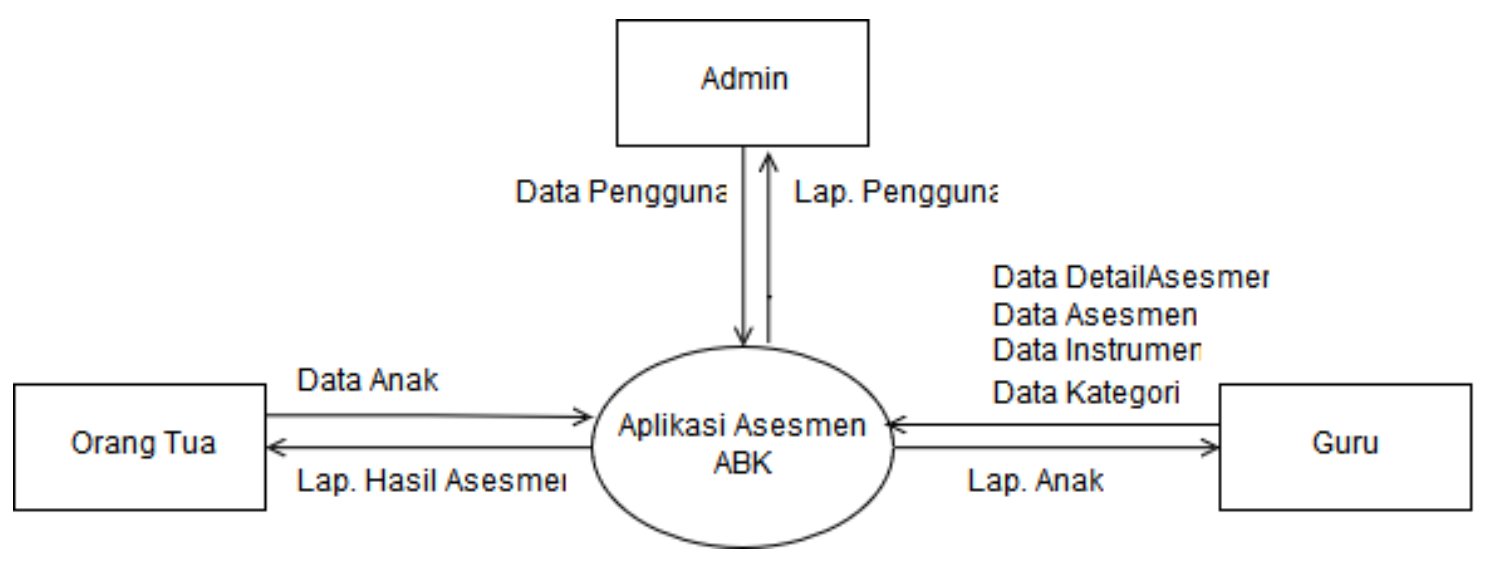

Gambar. 2. Diagram Konteks 


\section{Rancangan Sistem}

Sistem dibangun dengan konsep database relasional dimana terdapat beberapa table yang berhubungan satu sama lain dalam bentuk kunci primary dan kunci foreign dan dengan sifat one to many. Relasi tabel dari sistem yang dibangun ditunjukkan oleh Gambar 3.

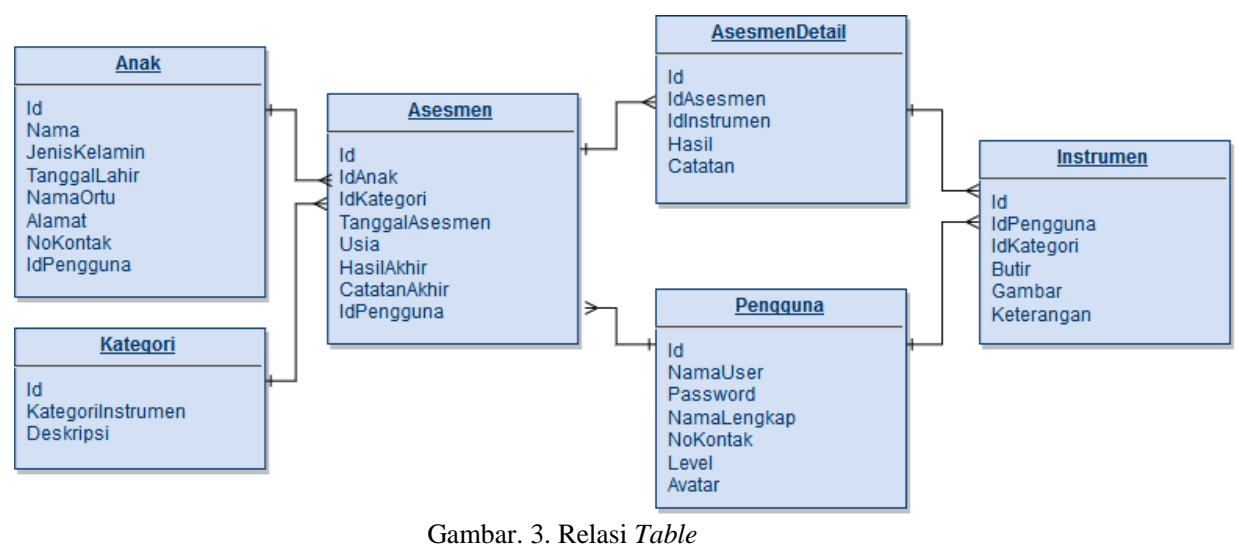

IV. HASIL DAN PEMBAHASAN

\section{A. Implementasi Sistem}

1) Halaman Login

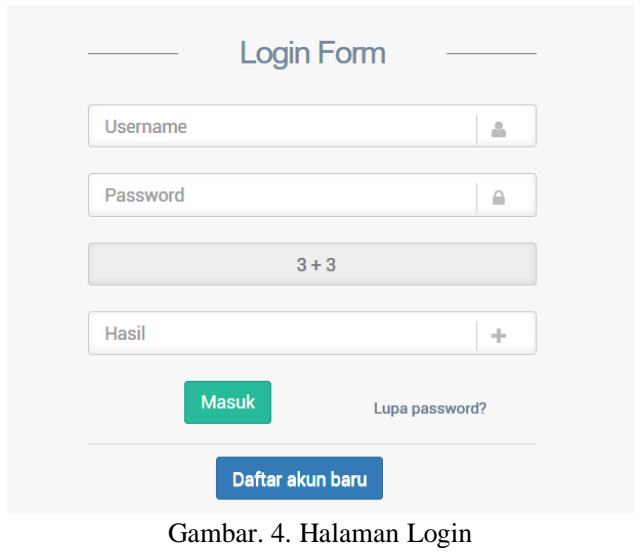

Halaman login melakukan proses pemilahan antara user Admin, Guru dan Orang tua, proses pemilahan ini berdasarkan pada data yang sudah dimasukkan pada proses pendaftaran pengguna. Halaman login juga mengandung captcha yang dibuat secara random berupa operasi matematika yang berfungsi meminimalisir terjadinya serangan pada proses ini seperti ditunjukkan pada Gambar 4.

\section{2) Halaman Utama}

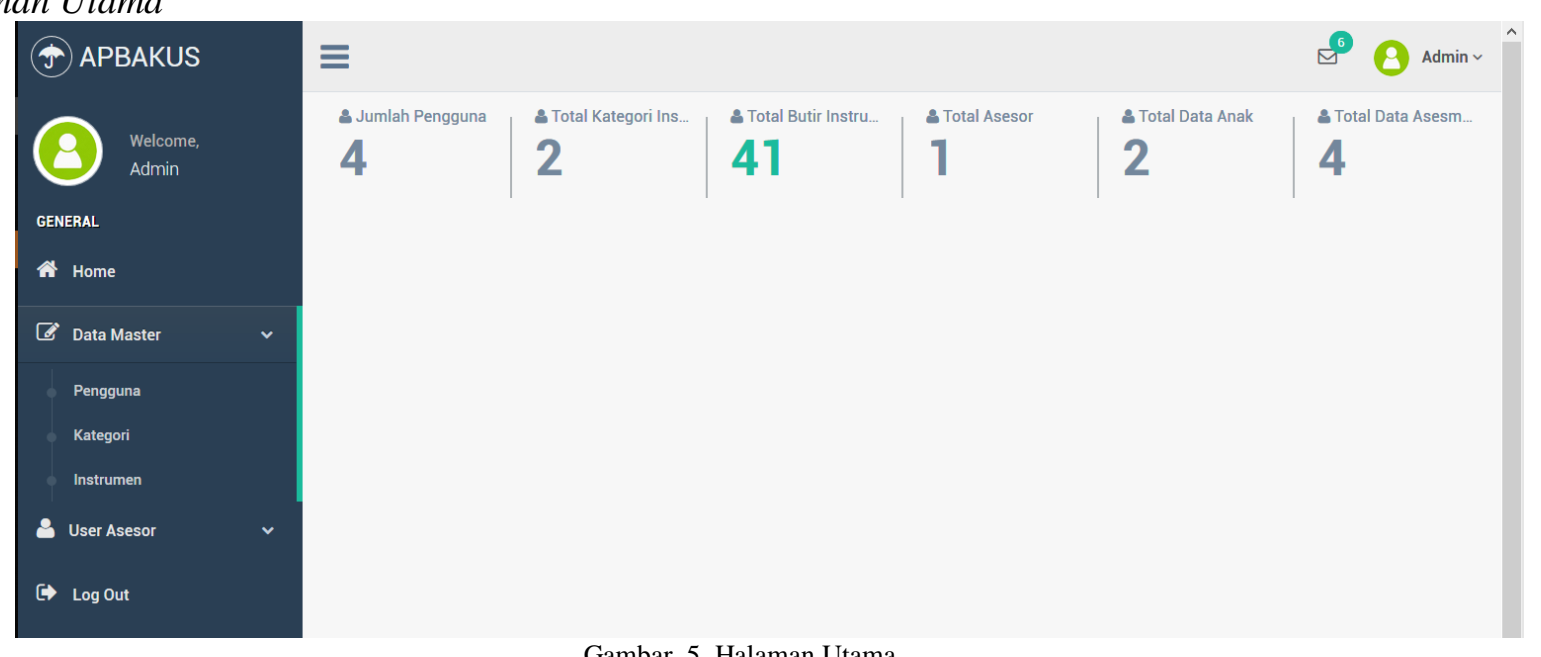

Gambar. 5. Halaman Utama 
Halaman ini menampilkan rekapitulasi jumlah data dan ditampilkan setelah user sukses melakukan login seperti ditunjukkan pada Gambar 5.

\section{3) Halaman Instrumen}
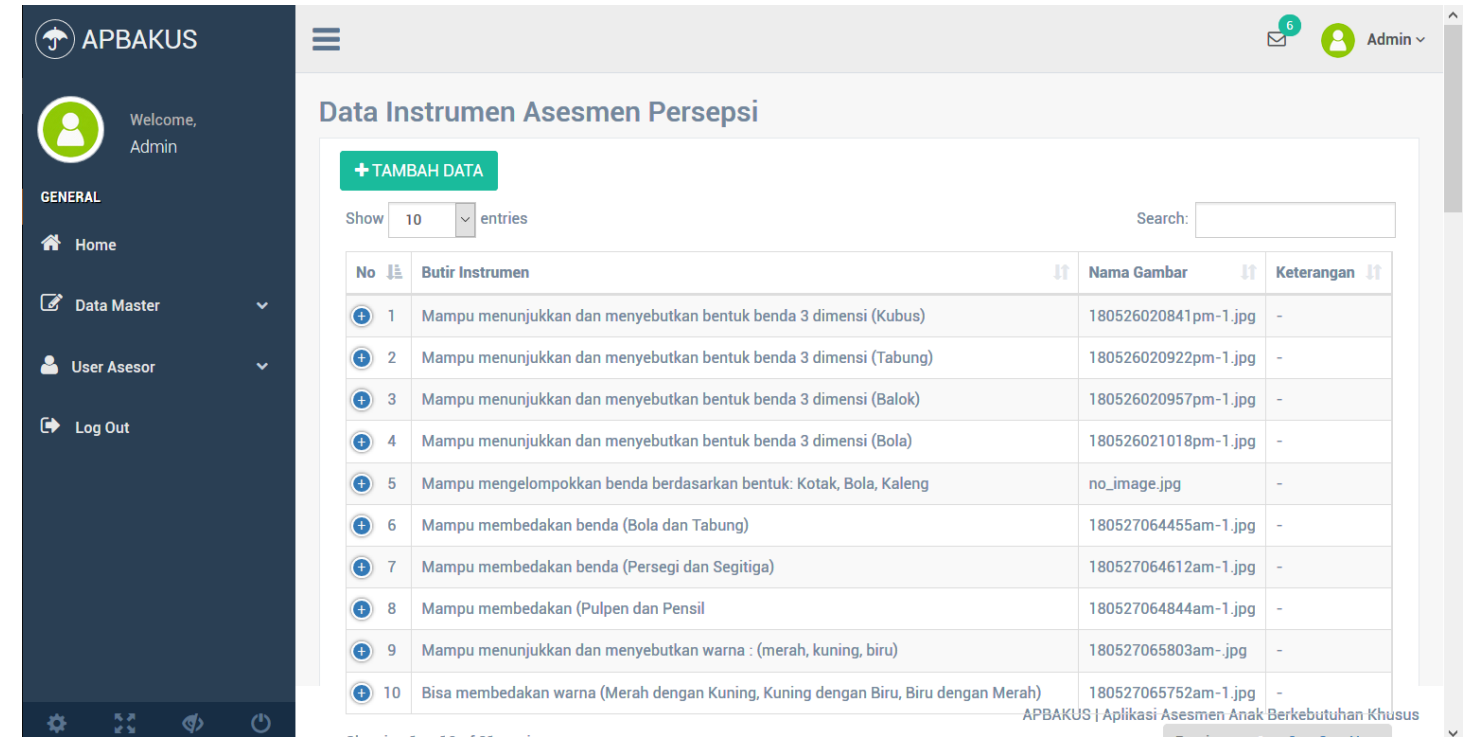

Gambar. 6. Halaman Instrumen

Halaman ini digunakan untuk menambah, menghapus, dan menampilkan data instrument asesmen yang dikelompokkan per kategori instrument seperti ditunjukkan pada Gambar 6.

\section{4) Halaman Asesmen}
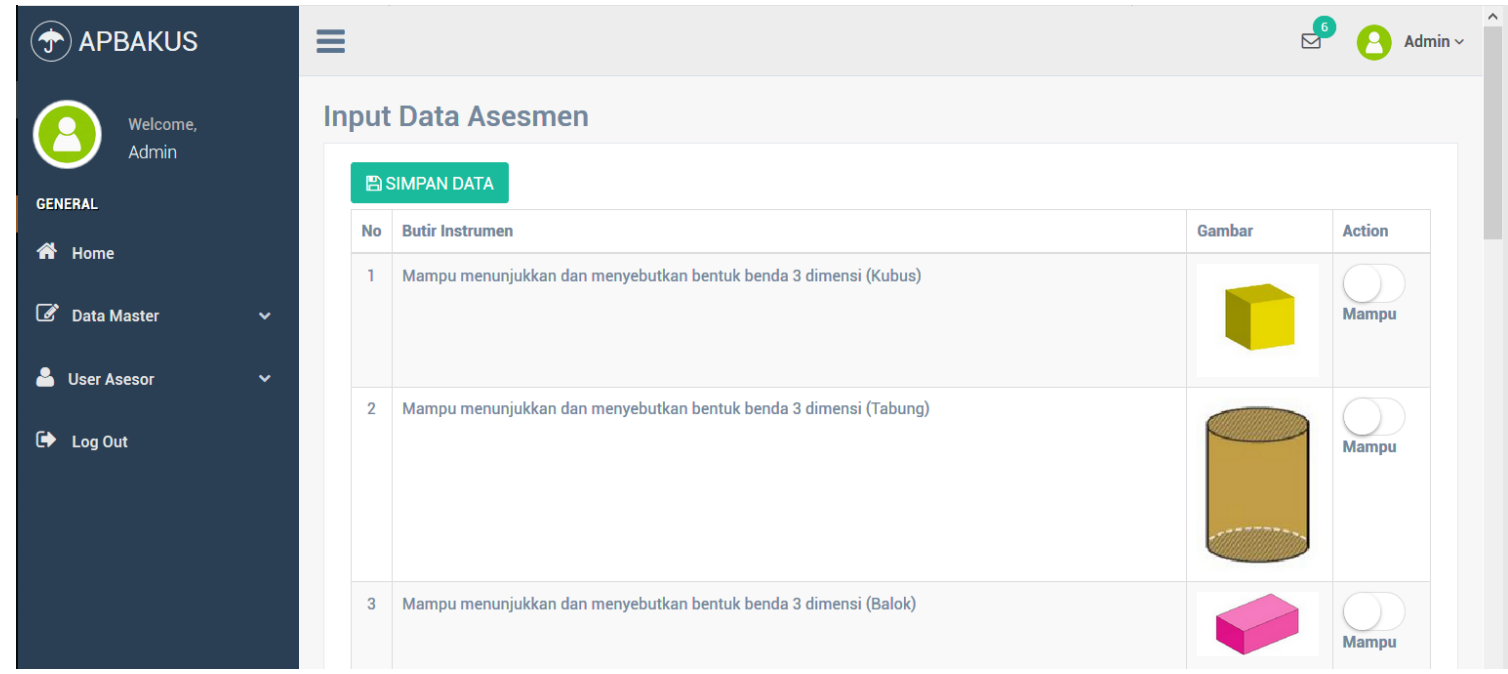

Gambar. 7. Halaman Asesmen

Gambar 7 menunjukkan tampilan halaman asesmen. Halaman ini digunakan untuk proses asesmen ABK, dengan terlebih dahulu mengisikan biodata $\mathrm{ABK}$ atau memilih data $\mathrm{ABK}$ jika sudah ada, kemudian memilih kategori instrumennya, dan dilanjutkan pada proses asesmen. Pertanyaan yang ditampilkan sesuai dengan kategori instrument yang dipilih.

\section{KESIMPULAN}

Aplikasi asesmen ABK mampu mendokumentasikan kegiatan asesmen sesuai dengan tahapan yang perlu dijalani, data $\mathrm{ABK}$ dan data asesmen tersimpan secara digital sehingga proses pencarian dan menampilkan data menjadi jauh lebih mudah. Aplikasi tidak memutuskan hasil asesmen secara langsung dan tetap memerlukan analisis dari GPK, hal ini dikarenakan hasil asesmen bersifat sensitif dan perlu kepakaran dan keluwesan manusia dalam memutuskan dan memberikan catatan terhadap hasil asesmen. 


\section{UCAPAN TERIMA KASIH}

Penulis mengucapkan terima kasih kepada Kementerian Riset, Teknologi, dan Pendidikan Tinggi, Program Studi Pendidikan Luar Biasa Universitas Lambung Mangkurat, dan Universitas Islam Kalimantan Muhammad Arsyad Al Banjari. Penelitian ini dibayai oleh RISTEK-DIKTI pada skema Penelitian Dosen Pemula dengan nomor DIPA SP DIPA-042.06.1.401516/2018 dan nomor kontrak 113/UNISKA-LP2M/IV/2018 dengan judul "Rancang Bangun Aplikasi Asesmen Anak Berkebutuhan Khusus pada Sekolah Inklusif’.

\section{DAFTAR PUSTAKA}

[1] S. Elisa and A. T. Wrastari, "Sikap Guru Terhadap Pendidikan Inklusi Ditinjau dari Faktor Pembentuk Sikap," Jurnal Psikologi Perkembangan dan Pendidikan, pp. 1-10, 2013.

[2] T. Sundari and M. Abdurrahman, Modul Asesmen ABK 08, Bandung: Fakultas Ilmu Pendidikan Jurusan Pendidikan Khusus Universitas Pendidikan Indonesia, 2013.

[3] U. Fadilah, J. W. Agustiawan and E. Sudarmilah, "Pembuatan WEB Sistem Pakar untuk Identifikasi dan Penanganan Anak Autis," Universitas Muhammadiyah Surakarta, Surakarta, 2011.

[4] H. Jamaludin, "Aplikasi Metode Certainty Factor pada Pengembangan Sistem Pengklasifikasi Anak Berkebutuhan Khusus," Jurnal Sistem Informasi Bisnis, pp. 132-143, 2013.

[5] A. G. Pratydina, "Sistem pendukung Keputusan Pemilihan Terapi untuk Anak Berkebutuhan Khusus dengan Metode Promethee," Universitas Dian Nuswantoro, Semarang, 2013.

[6] D. Gunawan and M. Indahsari, "Pengembangan Keterampilan Gerak Dasar Motorik Kasar Melalui Pembelajaran Seni Tari Kipas pada Anak Tunarungu," Jurnal Penelitian Pendidikan, pp. 32-39, 2016.

[7] Hermanto, "Kemampuan Guru dalam Melakukan Identifikasi Anak Berkebutuhan Khusus di Sekolah Dasar Penyelenggara Pendidikan Inklusi," Universitas Negeri Yogyakarta, Yogyakarta, 2010.

[8] D. M. C. Dewi, "Identifikasi Kemampuan Berbahasa Anak Autis di Sekolah Inklusif SD Negeri Giwangan Yogyakarta," Fakultas Ilmu Pendidikan Universitas Negeri Yogyakarta, Yogyakarta, 2014. 